DIGITALCOMMONS

$@$ WAYNESTATE-
Michigan Journal of Counseling:

Research, Theory and Practice

$1-1-2012$

\title{
Neglect, Physical and Sexual Abuse: A Look at Posttraumatic Stress Disorder in Children and Adolescents
}

Kelsey R. Beals

Clemson University, kbeals@clemson.edu

David A. Scott

Clemson University, dscott2@clemson.edu

Follow this and additional works at: https://digitalcommons.wayne.edu/mijoc

\section{Recommended Citation}

Beals, K. R., \& Scott, D. A. (2012). Neglect, Physical and Sexual Abuse: A Look at Posttraumatic Stress Disorder in Children and Adolescents, Michigan Journal of Counseling, 39(1), 31-38. doi:10.22237/mijoc/1325376180

This Article is brought to you for free and open access by the Open Access Journals at DigitalCommons@WayneState. It has been accepted for inclusion in Michigan Journal of Counseling: Research, Theory and Practice by an authorized editor of DigitalCommons@WayneState. 
Neglect, Physical and Sexual Abuse:

A Look at Posttraumatic Stress Disorder in Children and Adolescents

Kelsey R. Beals

Clemson University

David A. Scott

Clemson University

Abstract

This article focuses on Posttraumatic Stress Disorder that is largely overlooked in the counseling field and literature, specifically in children and adolescents. Etiology, treatment options, and the course in which the disorder manifests itself holds great importance in understanding the grave effects these traumatic events have on youth. This article is the beginning attempt to begin to understand how children exhibits symptoms of PTSD in order to work collaboratively with those involved in the child's life before it develops into a chronic maladaptive state.

Alternatively known as "shell shock" or "combat neurosis", Posttraumatic Stress Disorder (PTSD) has long been around, but has not always been recognized as a disorder in the world psychiatric classifications. With PTSD being identified with war, the idea that other traumatic events could cause detrimental symptoms was often disregarded. This belief was especially geared towards children and adolescents. Although the idea of PTSD symptoms being present in youth was thoroughly examined, nothing concrete was commenced until Terr $(1979,1983)$ conducted a study examining a group of children who were kidnapped and held hostage. These outcomes provided support that children and adolescents could develop PTSD. The four-year follow up study that took place in 1983 examined how the severity of the incident and children's posttraumatic symptoms interacted with the individual's history. This study led to the groundbreaking notion that PTSD symptoms can be present in children and adolescents as well as developing an initial understanding of the effect trauma can have on this population

Kelsey R. Beals is a graduate student in the Clinical Mental Health Counseling Program at Clemson University. She may be contacted via email at kbeals@clemson.edu. David A. Scott, PhD, LPC, CDFI is currently an Assistant Professor at Clemson University. Correspondence concerning this article should be addressed to David A. Scott at Counselor Education Program, 304-E Tillman Hall, Clemson University, Clemson, SC 29634-0707, email: dscott2@clemson.edu. 
According to the American Psychiatric Association (DSM-IV-TR), "Posttraumatic Stress Disorder (PTSD) is characterized by the re-experiencing of an extremely traumatic event accompanied by symptoms of increased arousal and by avoidance of stimuli associated with the trauma" (APA, 2000, pp. 468469). Although there are minimal studies available regarding Posttraumatic Stress Disorders, it is known that this disorder is highly prevalent in a wide range of settings, most commonly those related to sexual abuse (Stien, ZunguDirwayi, Van Der Linden, \& Seedat, 2000). With the enormous personal and societal costs PTSD takes from individuals and their families, the disorder must be examined from a multifaceted perspective.

In the United States an immense number of children are involved in traumatic events in the early years of their lives. Approximately 5.5 million children are involved in some sort of maltreatment case every year (Hamblen \& Barnett, 2010). Of these traumatic events reported in 2009, 78 percent were due to neglect, 18 percent were due to physical abuse, 10 percent to sexual abuse, and 8 percent to psychological abuse (Gaudiosi, 2009). These percentages total more than 100 percent because children who were victims of more than one type of maltreatment were counted for each type of maltreatment they experienced (Gaudiosi, 2009). These statistics show the intense reality of abuse in the United States. With many of these cases resulting in the diagnosis of PTSD or posttraumatic symptoms, the awareness of the treatments available, course the disorder takes, and diversity issues are critical issues for mental health professionals.

To be a child or adolescent diagnosed with PTSD, there is a list of criteria that must be met. The child or adolescent must have experienced, witnessed, or been confronted with an event or events that involved actual or threatened death, serious injury, or physical integrity of self or others (DSM-IV$T R, 2000)$. In children, PTSD manifests in responses of disorganized or agitated behavior and possible feelings of intense fear or helplessness (DSM-IV-TR, 2000). Frightening dreams often occur along with distressing recollections associated to the traumatic event. The child or adolescent will experience persistent avoidance of the stimuli associated with the traumatic event and often might have difficulty concentrating (i.e, in school) and have exaggerated startled responses (DSM-IV-TR, 2000). There are three main risk factors that enhance the likelihood of a child or adolescent developing PTSD after a traumatic event. These factors include the severity of the traumatic event, the parental reaction to the traumatic event, and the physical proximity to the traumatic event (Birmaher, Brent, \& Benson, 1998). The awareness of these risk factors is important to families and loved ones so they are able to be supportive, understanding of the symptoms, and even participate in the therapy process.

Although the symptoms and warning signs of PTSD in children are definite, the onset of when PTSD occurs can fluctuate. A study of 200 adolescents who survived the sinking cruise ship, Jupiter, provides support for this idea. There was a reported incident of PTSD in 51 percent of the survivors and most cases manifested within the first few weeks (Dyregrov \& Yule, 2006). Although delayed onset was less common, it was still present in the study. The time of the onset provided no connections with other factors, such as severity of the 
The diagnosis of PTSD in children and adolescents is parallel to that of adults. Even with these similarities, there are many factors related to any individual, adult or youth, that can enhance or decrease the probability of the occurrence of traumatic events that possibly cause PTSD symptoms. An interesting topic to look at is PTSD in children and adolescents that are lesbian, gay, bisexual, and transgender. Due to these individuals' distinctive characteristics, they are often ostracized and ridiculed for being different than the norm. D'Augelli, Grossman, and Starks (2006) conducted a study, "exploring the relationship between lesbian, gay, and bisexual youths' histories of victimization based on their sexual orientation, their gender atypicality in childhood and their current mental health, especially trauma-related symptoms" (p. 1). In the study, the adolescents (mean age was 17) were asked about sexual, verbal, and physical violence related to one's sexual orientation. Verbal sexual orientation violence (SOV) involved being name called, teased, or threatened. Physical SOV was assessed by inquiring if the adolescent had ever been punched, kicked or beaten with fists or weapons due to their sexual orientation. Finally, adolescents were asked about sexual SOV with questions about rape or sexual abuse because of their sexual orientation (D'Augelli et al., 2006).

A battery of tests were used to fully evaluate the participants in the study. The Brief Symptom Inventory (BSI), the Global Severity Index (GSI), and the Trauma Symptom Checklist (TSC) were the three tests used to inquire about current mental health problems in the adolescents. PTSD was evaluated by using the Diagnostic Interview Schedule for Children (DISC). Data gathered from the study showed that three fourths of the participants reported verbal SOV, 11 percent reported physical SOV and 9 percent reported sexual SOV (D'Augelli et al., 2006). While interviewing these adolescents, males reported significantly more sexual orientation violence of all types. Of both the females and males that experienced sexual SOV in this study, the majority of them reported being victimized by a friend or an acquaintance. Although there was no significant correlation between knowing the abuser and the diagnosis of PTSD, it is possible the prior relationship could be a contributing factor to the symptom of isolation during the onset of PTSD. Although this was a small sample size compared to the amount of children and adolescents in the LGBT community, the percentages are still disturbing. According to the study, out of the total 517 youth participants, 9 percent $(n=48)$ met the Diagnostic Interview Schedule for Children (DISC) criteria for a diagnosis of PTSD (D'Augelli et al., 2006). Although all types of sexual orientation violence contribute to traumatic symptoms in an individual, all youth diagnosed with PTSD reported more experiences with sexual SOV than any of the others (D'Augelli et al., 2006).

With the still relevant marginalization of gay, lesbian, bisexual and transgendered individuals, awareness must be made to the significant feelings of hopelessness and isolation that will continue to increase during these individuals' adolescent years. Abuse and neglect often add chronic stress to LGBT individuals' lives. Between the volatile path peer relationships take and the disappointment often expressed by parents, these individuals are at- risk for deterioration in many aspects of their lives. 
There is still much research that needs to be conducted to better understand the multiple aspects of how SOV is related to a diagnosis of PTSD. Also noteworthy in the study is the significant association between sex and verbal SOV. More specifically, a male that had been called a "sissy" while growing up experienced significantly more verbal SOV than other males throughout their adolescent years (D'Augelli et al., 2006). Interestingly, there was no significant association with females being called gender-altering names such as "tomboys" and verbal SOV. Despite the fact that females often did not experience more verbal SOV, females have a diagnosis of PTSD three times more often than males (D'Augelli et al., 2006). This finding has been corroborated through many studies. One of the contributing studies was Kilpatrick, Ruggiero, Acierno, Saunders, \& Resnick's (2003) investigation on interpersonal violence in adolescents. In this study, roughly twice the percentage of girls than boys met criteria for PTSD, with females reporting 6.3 percent and males reporting 3.7 percent.

Common co-morbidities among youth with PTSD are major depressive episodes, substance abuse and substance dependence (Kilpatrick et al. 2003). In a national survey of adolescents looking at exposure to interpersonal violence, PTSD was more likely to be co-morbid than were major depressive episodes, substance abuse and substance dependence (Kilpatrick et al., 2003). With this information, it is important for mental health professionals to be knowledgeable about the treatments available and what is most holistically effective in therapy with youth.

\section{Treatment}

In an ideal situation, prevention would be preferred over treatment when dealing with any psychological disorder. Because that is not always possible with traumatic events, early intervention is key in the treatment process. In intervening early it is possible to stimulate family communication around the events that have taken place and thus clarify any misunderstandings, prevent family secrets, and foster a good recovery environment for the children as well as for the family (Dyregroy \& Yule, 2006). Not only does early intervention help foster relationships within the family, but if the incident(s) are left untreated PTSD may run a chronic course for at least five years in more than one third of children who develop this disorder (Smith, Yule, Perrin, Tranah, \& Dalgleish, 2007). This state of constant distress, shame, and negative self- attribution will take a toll on the daily functioning of any individual who has experienced something traumatic and may adopt maladaptive behaviors. Along with the impairment of daily functioning, the individual may develop depressive symptoms, suicidal ideations and various other personality changes the longer the disorder is disregarded (Dyregroy \& Yule, 2009). Treatment options are varied among individuals. Medication along with preventative and remedial approaches provide a comprehensive method in coping with these experiences.

\section{Medication}

Incorporating medication along with psychotherapy when dealing with PTSD can be effective, especially because of the high co-morbidity rate PTSD has with depression and other disorders. Because the chemicals in the brain affect the way one feels, medication is an option to help balance those chemi- 
cals. The largest trials showing efficacy have been with selective serotonin reuptake inhibitors (SSRIs) (Stein et al., 2000). Medication such as Prozac and Zoloft are examples of SSRI's that are used frequently in the public. Specifically to children and adolescents, there has been limited research on the use of medication for PTSD symptoms. A study comparing the effects of citalopram (an SSRI) in children and adults is one of few in the literature. In this study, both children and adults showed significant reductions in measures of PTSD symptoms after the eight-week trial (Seedat et al., 2002). Krystal et al. (2011) found that newer antipsychotic medications (such as risperidone) were no more effective in treating PTSD in veterans than placebo. Although proven to be helpful with core symptoms, some research indicates the importance the combination of psychotherapy with medication for treatment of PTSD to be fully effective. Clearly, more research is needed to determine effective psychopharmacological treatments for children and adolescents. Additionally, the complexity of medication and children and adolescents requires caution.

\section{Psychotherapy}

An aspect to fully consider when in treatment is the familial influences on the children and adolescents. In addition to the social influences parents have on their children, there may also be inherited dispositions that have been passed down through generations (Dyregrov \& Yule, 2006). This highlights the importance of family involvement in the treatment process. Family members often cope with the traumatic event through avoidance and deflection in hopes of protecting the child. These actions prohibit the whole family from processing and working through the experience.

Although family involvement is important in getting the dynamics back into place after a traumatic event, Cognitive Behavioral Therapy (CBT) has proven to be a beneficial therapy when working with children and adolescences that suffer from PTSD (Smith et al. 2007). A variety of different methods within the realm of CBT have been used when dealing with PTSD and have proven to be critical in the treatment process (Dyregrov \& Yule, 2006). More specifically, Trauma-Focused Cognitive Behavioral Therapy (TF-CBT) has become more widespread in the treatment of PTSD in children. TF-CBT is a cojoint child and parental approach for children and adolescents, ages 3-18, who have experienced extreme emotional and behavioral impediments due to traumatic life events (National Crime Victims Research \& Treatment Center, 2010). This approach incorporates trauma-sensitive interventions with cognitive behavioral, family, and humanistic principles and techniques.

TF-CBT is especially useful in dealing with children and adolescents who have been sexually abused. According to Cohen, Deblinger, Mannarino, and Steer (2004), using TF-CBT reduced PTSD, depression, and the total number of behavioral problems compared to a child-centered treatment approach for children who were sexually abused. Learning new coping skills to help process their thoughts and feelings is one aspect of TF-CBT that helps open groundwork for progress to be made. According to Dyregrov and Yule (2006), "twice as many children ages 8 to 14 years receiving the child centered treatment still met the criteria for PTSD compared to those who received TraumaFocused Cognitive Behavioral Therapy" (p. 180). 
There has been much debate and research on alternate approaches to be used with children and adolescents suffering from traumatic events. One alternate approach used is Eye Movement Desensitization and Reprocessing (EMDR). Like other types of therapy, EMDR makes an effort to alter the way an individual reacts to traumatic memories. Studies have shown that EMDR may help lessen the PTSD symptoms, but research also suggests that the eye movements are not a necessary part of the treatment (Hamblen \& Barnett, 2010).

Although there are other options out there, TF-CBT provides empirical evidence in helping children and adolescents with their disorder. The TF-CBT approach effectively treats PTSD and is reported to be more effective than Client Centered Therapy in reducing abuse-related attributions and shameful feelings (Cohen et al., 2004). The elements in TF-CBT encourage individuals to recognize relationships between their thoughts and learn how to cope with them in a healthy manner. There are also often joint parent-child sessions to allow the child and parent to share and discuss the traumatic event with one another (Cohen et al., 2004).

A key component of the TF-CBT approach with PTSD is that it is recommended to help treat acute posttraumatic reactions in children and adolescents as well. With this information, it is unnecessary to wait for the onset of PTSD to occur. Treatment can begin immediately after the event if necessary. The benefit of being able to start therapy early brings in the early intervention positive qualities to diminish the possibility of chronic symptoms.

CBT is not just bound to the individual approach when dealing with PTSD. It has also been proven beneficial in a group setting of children with PTSD or PTSD symptoms. Game-Based Cognitive Behavioral Therapy (GBCBT) is a productive approach when working with a group of youth who have been victim to sexual abuse. GB-CBT was designed to address the potential behavioral problems and symptoms typically associated with child sexual abuse and works to enhance children's knowledge of abuse and self-protection skills (Springer \& Misurell, 2010). With the knowledge that most youth isolate themselves from friends and family after a traumatic experience, the interaction with other peers could be helpful in allowing them to gradually work their way back to their original baseline behaviors. Kaduson and Scheafer (2006) emphasized that enhanced feelings of safety and empowerment must also be incorporated in the approach in which the therapist interacts with the children. Along with this, the therapists' consistent portrayal of respect, acceptance and faith is of great importance to keep a positive group dynamic. If the environment provides these characteristics, these consistent positive interactions could stimulate their desire to accept the role in the family.

\section{Conclusion}

An inestimable number of components that trauma is comprised of can bring a negative impact on any individual. With children and adolescents suffering from PTSD being a relatively new concept, great efforts have been made in attempt to understand PTSD and how to prevent it from turning into a chronic maladaptive state. 
Suffering from PTSD can affect a person in numerous ways throughout the United States. Whether it is a friend, family member, or a personal experience, enduring the pain and impairment of daily routines can lead to a helpless and hopeless thought process. This cycle can continue to create damaging effects and prohibit the growth made during adolescence. Studies show that up to 43 percent of boys and girls go through at least one trauma and of those children and adolescents who have experienced a trauma, 3-15 percent of girls and 1-6 percent of boys develop PTSD (Hamblen \& Barnett, 2010). Being cognizant of what PTSD is and the signs it possesses can be crucial to the early treatment intervention that would help the child or adolescent reestablish normalcy. Also, understanding the way in which this disorder establishes itself within an individual can be very helpful. Although there is much room for growth, overall there has been great progress in the discovery of PTSD since its recent recognition in the DSM-IV-TR as a psychiatric illness.

\section{References}

American Psychiatric Association. (2000). Diagnostic and statistical manual of mental disorders (Revised 4th ed., pp. 468-469). Washington, DC: American Psychiatric Association.

Birmaher, B., Brent, D., \& Benson, R. S. (1998). Summary of the practice parameters for the assessment and treatment of children and adolescents with depressive disorders. Journal of the American Academy Child and Adolescent Psychiatry, 37(11), 1234-1238.

Cohen, J. A., Deblinger, E., Mannarino, A. P., \& Steer, R. (2004). A multi-site, randomized controlled trial for children with abuse-related PTSD symptoms. . Journal of the American Academy Child and Adolescent Psychiatry, 43(4), 393-402.

D'Augelli, A.R., Grossman, A.H., \& Starks, M.T. (2006). Childhood gender atypicality, victimization, and PTSD among lesbian, gay and bisexual youth. Journal of Interpersonal Violence, 21(11), 1462-1482. doi: $10.1177 / 0886260506293482$

Dyregrov, A., \& Yule, W. (2006). A review of PTSD in children. Child and Adolescent Mental Health, 11(4), 176-184., doi: 10.1111/j.14753588.2005.00384.x

Gaudiosi, J.A. (2009). U.S. Department for Children and Families, Administration on Children, Youth and Families. Child maltreatment 2009. Washington, DC: NCANDS. Retrieved from http://www.acf.hhs.gov/programs/ cb/stats_research/index.htm\#can

Hamblen, J., \& Barnett, E. (2010, June 15). PTSD in children and adolescents. Retrieved from http://www.ptsd.va.gov/professional/ pages/ ptsd_in_children_and_adolescents_overview_for_professionals.asp 
Kaduson, H., \& Schaefer, C. E. (2006). Short term play therapy for children. (2 ed., pp. 250-254). New York, NY: A Division of Guilford Publications, Inc.

Kilpatrick, D.G., Ruggiero, K.J., Acierno, R., Saunders, B.E., \& Resnick, H.S. (2003). Violence and risk of PTSD, major depression, substance abuse/dependence, and comorbidity: Results from the national survey of adolescents. Journal of Counseling and Clinical Psychology, 71(4), 692-700. doi: 10.1037/0022-006X.71.4.692

Krystal, J. H., Rosenheck, R. A., Cramer, J. A., Vessicchio, J. C., Jones, K. M., Vertrees, J. E., \& Stock, C. (2011). Adjunctive risperidone treatment for antidepressant-resistant symptoms of chronic military service-related PTSD: A randomized trial. Journal of the American Medical Association, 306, 493-502. doi:10.1001/jama.2011.1080

National Crime Victims Research \& Treatment Center (2010). Project best: Bringing evidence supported treatments to South Carolina children and families. (2010). Retrieved from http://academicdepartments.musc.edu/ projectbest/tfcbt/tfcbt.htm

Seedat, S., Stein, D. J., Ziervogel, C., Middleton, T., Kaminer, D., Emsley, R. A., \& Rossouw, W. (2002). Comparison of response to a selective serotonin reuptake inhibitor in children, adolescents, and adults with posttraumatic stress disorder. Journal of Child and Adolescent Psychopharmacology, 12(1), 37-46. doi: doi:10.1089/10445460252943551

Smith, P., Yule, W., Perrin, S., Tranah, T.,\& Dalgleish, T. (2007). Cognitivebehavioral therapy for PTSD in children and adolescents: a preliminary randomized controlled trail. Journal of the American Academy Child and Adolescent Psychiatry, 46(8), 1051-1061. doi:10.1097/ CHI.0b013e318067e288

Springer, C., \& Misurell, J. C. (2010). Game-based cognitive-behavioral therapy (GB-CBT): An innovative group treatment program for children who have been sexually abused. Journal of Child and Adolescent Trauma, 3 (3), 163-180. doi: 10.1080/19361521.2010.491506

Stein , D. J., Seedat, S., Van Der Lindon, G. J., \& Zungu- Dirwayi, N. (2000). Selective serotonin reuptake inhibitors in the treatment of posttraumatic stress disorder: a meta-analysis of randomized controlled trials. International Clinical Psychopharmacology, 15(Suppl. 2), 31-39.

Terr, L.C. (1979). Children of Chowchilla. A study of psychic terror. The Psychoanalytic Study of the Child, 34, 547-623.

Terr, L.C. (1983). Chowchilla revisited: The effect of psychic trauma four years after a school-bus kidnapping. American Journal of Psychiatry, 140, 1543-1550. 